\title{
Civil War: Front Line. La confrontación entre seguridad nacional y derechos civiles
}

\author{
Pau González Gost
}

Estudió Humanidades en la Universitat Pompeu Fabra especializándose en literatura y filosofía, cursó el Máster de Formación de Profesorado y en la actualidad está terminando un doctorado en Literatura y lenguas modernas sobre la figura de Fernando Pessoa. Ha publicado relatos de ficción en antologías de escritores jóvenes, artículos en periódicos locales y dos entrevistas: una a Max (Quimera) y otra a Pere Joan (La Bolsa de Pipas); también creó y llevó adelante varios blogs. Publicó un artículo en el sexto número de CuCo, Cuadernos de cómic: «La katábasis de Max y Bernat Metge». En la actualidad trabaja como profesor de secundaria de Literatura castellana y Filosofía.

Fecha de recepción: 5 de octubre de 2016

Fecha de aceptación definitiva: 18 de noviembre de 2016 


\title{
Resumen
}

En este artículo se estudia la influencia que los medios de comunicación tienen en la sociedad cuando se trata de influir para que se adopten medidas como la Patriot Act. Se plantea que los medios inclinan la balanza hacia el control y el miedo en el debate entre derechos civiles o seguridad nacional. Para adentrarnos en el tema tomaremos el crossover de Marvel Civil War: Front Line. Consideramos que el paralelismo entre la Patriot Act y el Acta de Registro de Superhéroes es evidente, y el papel de los medios de comunicación queda reflejado a partir de los protagonistas del crossover.

Palabras clave: Civil War, Front Line, Patriot Act , derechos civiles, seguridad nacional

\begin{abstract}
In this article we study the influence of mass media in society to influence opinions and get approved laws like the Patriot Act. We think that the media position is in favor of control and fear in the fight between civil rights and national segurity. To explore this idea we will take as example the Marvel crossover Civil War: Front Line. We consider that the similarities between the Patriot Act and the Superhuman Registration Act is obvious, and the mass media conduct is reflected through the protagonists actions.
\end{abstract}

Keywords: Civil War, Front Line, Patriot Act, civil rights, national security

\section{Cita bibliográfica}

GonzÁlez Gost, P. «Civil War: Front Line. La confrontación entre seguridad nacional y derechos civiles», en CuCo, Cuadernos de cómic n. 7 (2016), pp. 136-160. 


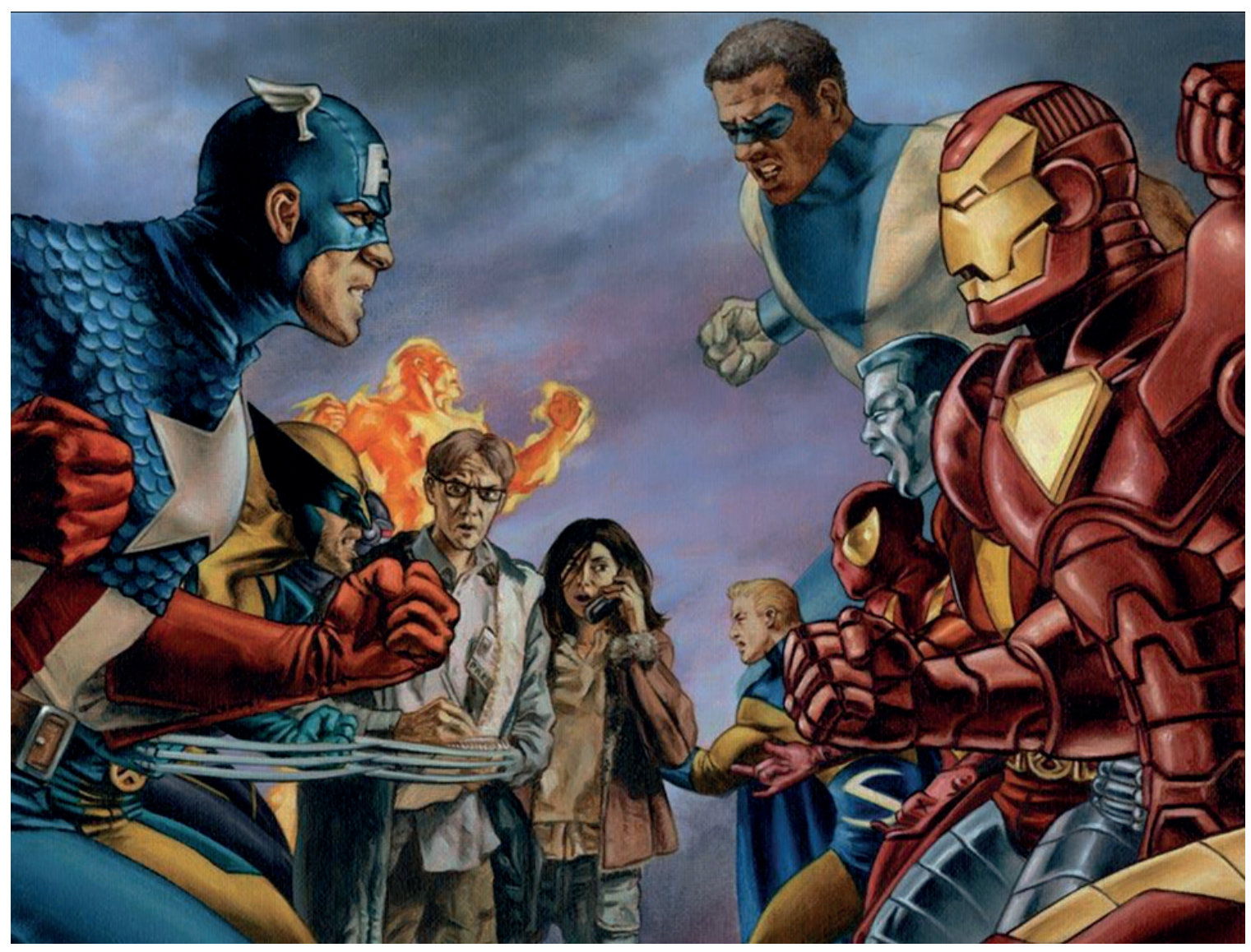

FIG. 1. Watson, J. Civil War: Front Line. Imagen extraída de Now is not the rhyme! Disponible en http://www.nowisnottherhyme.net/civilwarfrontline.

\section{Introducción}

El crossover Civil War empieza con el intento de detención de unos supervillanos por parte de unos superhéroes jóvenes (entre ellos Bola Veloz, del que hablaremos más adelante). E1 intento termina en una catastrófica explosión que arrasa una escuela y parte del barrio en el que está situada. A partir de ahí el gobierno decide que los superhéroes deben estar fichados y promulgan el Decreto de Registro de Superhumanos. Iron Man se pone a la cabeza de los 
superhéroes que apoyan la medida y el Capitán América encabeza la resistencia. El tema de fondo es si debe primar la seguridad nacional o los derechos civiles.

En este debate gana por su peso ético la defensa de los derechos. En lo concreto, parece ser que la gente está dispuesta a sacrificar su libertad para defender su propia seguridad. Esto se puede deber a que se ha revalorizado el concepto de seguridad en detrimento del de libertad.

Like freedom [...] power implies a potential or actual capacity for action; unlike rights, power may refer to a psychological state as well as to an objective condition [...]. Thus we can see the way freedom-talk could easily turn into power-talk and recognize the ambiguous but close relationship between the two concepts. ${ }^{1}$

Un ejemplo de esto son los lemas que se oyen en el metro de Barcelona: «por su propia seguridad, esta estación está dotada con cámaras de videovigilancia». La seguridad es un valor que justifica que el sujeto sea observado y controlado. Todo argumento que se da a favor del control es para aumentar la seguridad, y el control supone medidas contra aquellos que son problemáticos, no implica una más amplia comprensión del problema, sino una confrontación con él. Es decir, que en vez de ir a las causas por las que el lumpen actúa a través de la delincuencia se perpetúan estas causas intentando prevenirlas a través de medios de seguridad. En la película Buenos días: Ohâyo ${ }^{2}$ de Yasujiro Ozu encontramos otro ejemplo: el film retrata la vida de una pequeña comunidad japonesa y su manera de relacionarse a través del lenguaje. En un momento del film aparece un vendedor que intenta asustar a los habitantes de la comunidad sacando un cuchillo para que le compren cosas. Después pasa otro vendedor ambulante que vende sistemas de seguridad, y algunos habitantes compran porque se han sentido en riesgo recientemente. Al final del día, se ve como los dos vendedores se encuentran en el bar y se preguntan qué tal ha ido el día, con lo que se ve que trabajan juntos. Lo que confirma este ejemplo es la relación entre la seguridad y el miedo, o la necesidad de crear un estado de paranoia generalizada para aplicar a la vida cotidiana los criterios de la seguridad en vez de los de la libertad.

De la misma manera, en la nueva novela de Isaac Rosa, El país del miedo, ${ }^{3}$ encontramos al principio la descripción de este estado. Las voces de los dos protagonistas nos van describiendo los distintos miedos que les persiguen (miedo a que les roben, miedo de los inmigrantes, miedo de que a su hijo le pase algo...) y encontramos una situación parecida a la del film Buenos días: Ohâyo: se produce un robo en muchos pisos de la finca y días después aparece una empresa que se dedica a la instalación de aparatos de seguridad. Lo que se deduce es que el miedo y la necesidad de seguridad van siempre de la mano.

\footnotetext{
${ }^{1}$ KIng, R. H. Civil rights and the idea of freedom, Nueva York, Oxford University Press, 1992, p. 15.

2 Ozu, Y. Buenos días: Ohâyo. [DVD]. A contracorriente films, Shochiku, 2013.

3 Rosa, I. El país del miedo. Barcelona, Seix Barral, 2008.
} 


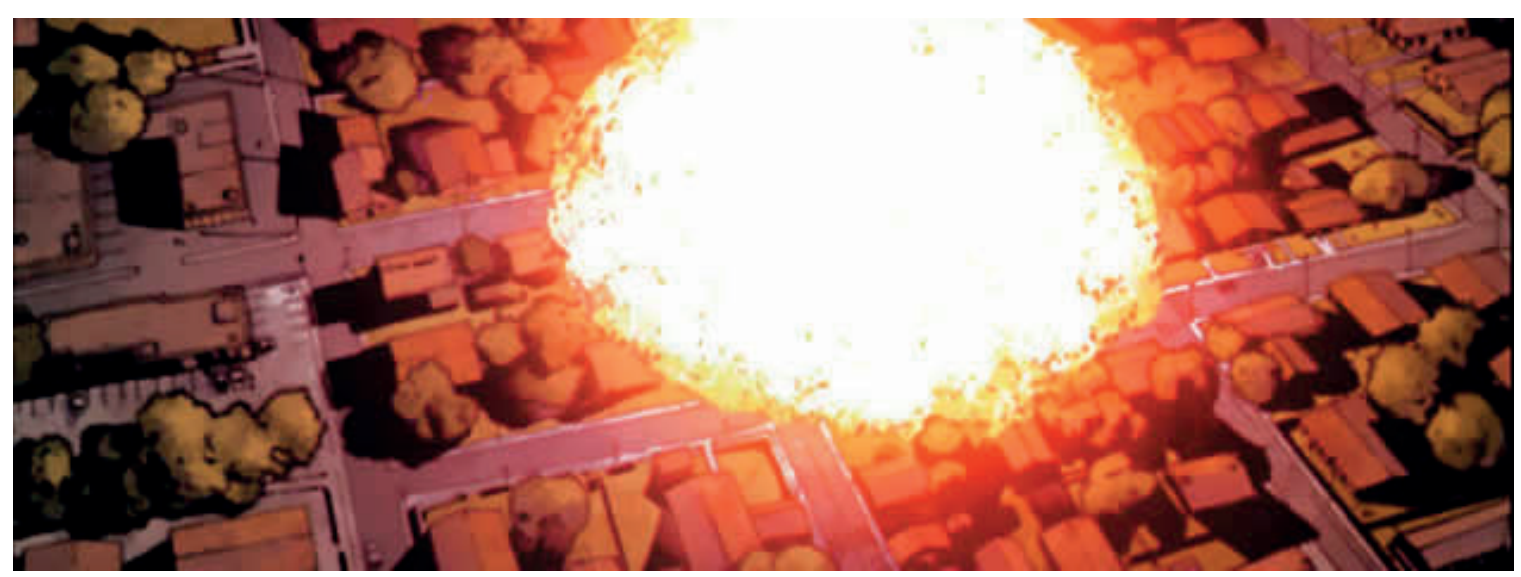

FIG. 2. Millar, M. y McNiven, S. Civil War.

Girona, Panini, 2007, p. 15.

\section{La telesociedad y sus consecuencias}

Considero que la opinión pública representa el estado de ánimo de la comunidad. Si esta comunidad se ve alterada por sentimientos de miedo asociados a unas personas que vienen de fuera, y a estos sentimientos se les suma el primordial y siempre fomentado odio hacia el extranjero, tenemos a una sociedad atacada a través de los nervios (sus ánimos) hacia unos individuos que automáticamente se convierten en molestos, porque nos recuerdan esas cosas que dicen por la televisión: delincuencia, integrismo, machismo, terrorismo, etc. Con todo este proceso de criminalización se crea el estado ideal para conseguir un racismo hacia el otro. Es decir: un racismo que va dirigido únicamente hacia los extranjeros (pobres). El racismo deshumaniza al grupo social que se odia o que se teme, convirtiéndolo en animal o en bárbaro. En el caso del grupo social negro se lleva a cabo una animalización que desde hace años actúa desde los mass media que se encargan de asociar a África un imaginario relacionado con la permanente inanición, las enfermedades infecciosas, y las barbaridades de guerras horribles, junto con la imaginería exótica relacionada con el mono y con los animales de la selva. Se trata de construir un África salvaje que incluya a sus habitantes como habitantes de lo salvaje animalizados. En el caso del grupo social musulmán, se lleva a cabo una barbarización moderna: el terrorismo. Al no ser del todo humanos, los individuos que pertenecen al grupo minoritario y reprimido, no tienen los mismos derechos que un «humano completo». Veamos esto con el caso de un documental: Els 11 del Raval. ${ }^{4}$ En el documental se ve reflejado el papel de los medios de comunicación en los casos de terrorismo islamista. Según el abogado defensor de los «11 del Raval» (Benet Salellas), en casos de supuesto terrorismo se procede de la siguiente manera: antes de nada se detiene a los individuos; mientras están retenidos, se empieza la investigación; y después, se da el veredicto. Es decir, detención, investigación y resolución. Se cambia el procedimiento tradicional de investigación, detención y resolución. ¿`Y qué es lo que hace invertir este procedimiento?

\footnotetext{
${ }^{4}$ Guàrdia, C. y López, P. Els 11 del Raval. [Documental de televisión]. Televisió de Catalunya, 2009. Disponible en http://www.tv3.cat/30minuts/reportatges/1250/Els-11-del-Raval.
} 
La piel de los detenidos. Se explicaban casos de falsificación de documentos en los que se procedía a detener anunciando que se estaba deteniendo a una célula terrorista, se hacía la investigación y los acusados quedaban libres de los cargos de terrorismo. Esto significa que se olvida el derecho a la presunción de inocencia, ya que según la procedencia se empieza con un cargo más. Lo que supone también una vulneración del séptimo artículo de la Declaración Universal de los Derechos Humanos: la igualdad de todos los hombres ante la ley. ¿Cómo crean los medios de comunicación masivos los sentimientos de miedo y odio que permiten la injusticia de la ley y la indiferencia del pueblo?

Antes de nada se intenta crear un estado de alarma permanente, a causa de la difusión de cargos que muchas veces resultan inventados. «Catastrophic risks, International terrorism, and national security intelligence has persuaded me that we live in a time of grave and increasing danger». ${ }^{5}$ Así es como prepara su argumentación Richard A. Posner: una argumentación que irá en detrimento de los derechos civiles y a favor del aumento de la seguridad nacional, con la recreación de un estado en perpetua alarma, en el que los servicios de inteligencia convencen a los jueces del camino a seguir. ${ }^{6} \mathrm{~A}$ pesar de su postura reaccionaria, el autor hace un análisis muy lúcido de las preocupaciones de los defensores de los derechos civiles y de la situación que se ha vivido en Estados Unidos desde el 11S:

The core meaning of «civil liberties» is freedom from coercive or otherwise intrusive governmental actions designed to secure the nation against real or, sometimes, imagined internal and external enemies. The concern is that such actions may get out of hand, creating a climate of fear, oppressing the innocent, stifling independent thought, and endangering democracy. ${ }^{7}$

La difusión a través de los medios de comunicación masivos de determinadas palabras, como terrorismo, explosivos, célula, islam/ista, integrista, etc., preparan la alarma y la desconfianza de la opinión pública que deja que sobre determinados individuos se recorten algunos de sus derechos (intimidad y habeas corpus, ${ }^{8}$ por ejemplo) para evitar lo que la fiscal María Dolores Delgado teme, y que en lenguaje popular se traduce como males mayores. Según este procedimiento se puede permitir lo que Posner llama una non-legal law of necessity (es un oxímoron

\footnotetext{
5 Posner, R. A. Not a suicide pact. The Constitution in a time of national emergency. Nueva York, Oxford University Press, 2006, p. 3.

${ }^{6}$ Richard A. Posner en su libro Not a suicide pact. The Constitution in a time of national emergency dice que la Constitución es una materia flexible que se tiene que adaptar entre dos ámbitos: el ámbito de la seguridad pública y la libertad personal. Describe la constitución como una balanza (imagen de la ley) que se desequilibra a favor de la seguridad pública en tiempos convulsos y se reequilibra en tiempos seguros.

7 Posner, R. A. Op. cit., p. 4.

8 «El habeas corpus es una institución jurídica que garantiza la libertad personal del individuo, con el fin de evitar los arrestos y detenciones arbitrarias. Se basa en la obligación de presentar ante el juez, a todo detenido en el plazo de 72 horas, el cual podría ordenar la libertad inmediata del detenido si no encontrara motivo suficiente de arresto [...]. También puede decirse que tutela los derechos fundamentales derivados de la vida y la libertad frente a cualquier acto u omisión de cualquier autoridad, funcionario o persona, que pueda vulnerar dichos derechos.» Disponible en http://es.wikipedia.org/wiki/Habeas corpus.
} 
al más puro estilo Borges: non-legal law $)^{9}$ que sería una ley supralegal que da carta blanca a determinados abusos físicos para evitar algo. Es como una ley moral que está por encima de la propia Constitución. El autor piensa que la Constitución es una materia flexible que se tiene que adaptar entre dos ámbitos: el ámbito de la seguridad pública y el de la libertad personal. Describe la constitución como una balanza que se desequilibra a favor de la seguridad pública en tiempos convulsos y se reequilibra en tiempos seguros. El libro es una defensa de la Patriot Act y sus consecuencias, argumentando siempre a favor de la seguridad pública.

La lucha contra el terrorismo internacional no es un cheque en blanco para el recurso a la fuerza, y no debe justificar, ni siquiera con el argumento de mal menor, de efectos colaterales, sus consecuencias letales para la democracia, como la criminalización de la disidencia, la reducción de los principios y reglas de juego del Estado de Derecho, la suspensión de garantías básicas de los derechos fundamentales como el habeas corpus. ${ }^{10}$

Lo que describe Consuelo R. Chornet es exactamente lo que ha pasado en el caso de la actual lucha antiterrorista. Los medios se encargan de difundir la supuesta culpabilidad del sujeto como si fuera ya culpable: difunden el presunto cargo de terrorismo como el motivo de la detención, con lo que el acusado es doblemente acusado; primero por la justicia y después por la opinión pública. No se vuelve a hablar del caso, o no lo hacen en portada. El efecto de estos fragmentos de noticias es que contribuyen a la atmósfera de miedo producida por los medios y sitúan a la población en un estado de alerta permanente que permite los abusos y la vulneración del habeas corpus.

Es ilustrativo el caso que se explica en el documental sobre los inmigrantes del Raval que celebraron el Milad Al-Nabi ${ }^{11}$ dentro del polideportivo del Raval. ¿Por qué se esconden unos sujetos para poder llevar a cabo sus libertades cultuales y religiosas? Porque aunque no sea ilegal ser musulmán se ha creado una non-legal law of necessity que prohíbe socialmente determinadas prácticas. El efecto arriba comentado de asociación de algunas ideas a algunas palabras consigue que la opinión pública, cada vez que ve algo que le recuerda a islamismo, piense en terrorismo, lo que produce un rechazo hacia aquellos que nos pueden recordar lo que nos da miedo.

\footnotetext{
9 «En mi opinión, la argumentación que pretende que el recurso a la guerra en la lucha contra el terrorismo sería una respuesta extrema, pero coherente con la legitimidad del recurso a la fuerza, es un auténtico oximoron, como el ejemplo más bello de esta figura retórica, el que nos ofrece Borges, la imagen del sol negro/Esta crítica, a mi juicio, puede dirigirse no sólo a la guerra contra el terrorismo, sino al resto de las que podemos denominar "guerras por la paz" [otro oxímoron], tanto a las denominadas guerras humanitarias como a las guerras preventivas o de defensa anticipatoria, que se basan a su vez en una perversión de la doctrina clásica de la legítima defensa en el orden internacional». En CHornet, C. R. Derechos y libertades ante las nuevas amenazas a la seguridad global. Valencia, Universidad de Valencia, 2005, p. 244.

10 Ibid. p. 253.

11 Se celebra el cumpleaños de Mahoma. Los musulmanes chiítas y sunitas celebran este día en días diferentes, normalmente cae con muy pocos días de diferencia. Las actividades que llevan a cabo este día son procesiones, banquetes, decoraciones y cuentacuentos. Disponible en http://www.raicesenbahrain.com/cultura arabe3A.htm.
} 
Hay una situación real de terrorismo internacional, hay una paranoia internacional entre la población y los gobiernos, y existen unos determinados intereses. Pero está claro que hay una voluntad interesada para consolidar un proceso que podemos llamar «convirtamos el islam en terrorismo». Para Robert E. Park la gran ciudad es un lugar de convergencia de intereses. ${ }^{12} \mathrm{Y}$ la opinión pública, «una forma de control fundamental en la sociedad moderna, que crea un clima social y orienta la conducta colectiva». ${ }^{13}$ De esta manera los intereses que tienen el control de la opinión pública pueden crear el clima que hemos visto. Quienes buscan esto son los defensores de la sociedad del control. «Pero si no podemos contar la verdad, porque al contarla pondríamos en peligro al periódico, ¡es que el sistema está seriamente viciado!», ${ }^{14}$ dice Ben, periodista de la saga Primera línea ${ }^{15}$ que se encarga de cubrir los acontecimientos de Civil War. Y esto es exactamente lo que pasa en Civil War, el sistema «está seriamente viciado», y se impide que se cuente la verdad ya que cualquier individuo que intenta contradecir el sistema es considerado un enemigo. ${ }^{16}$

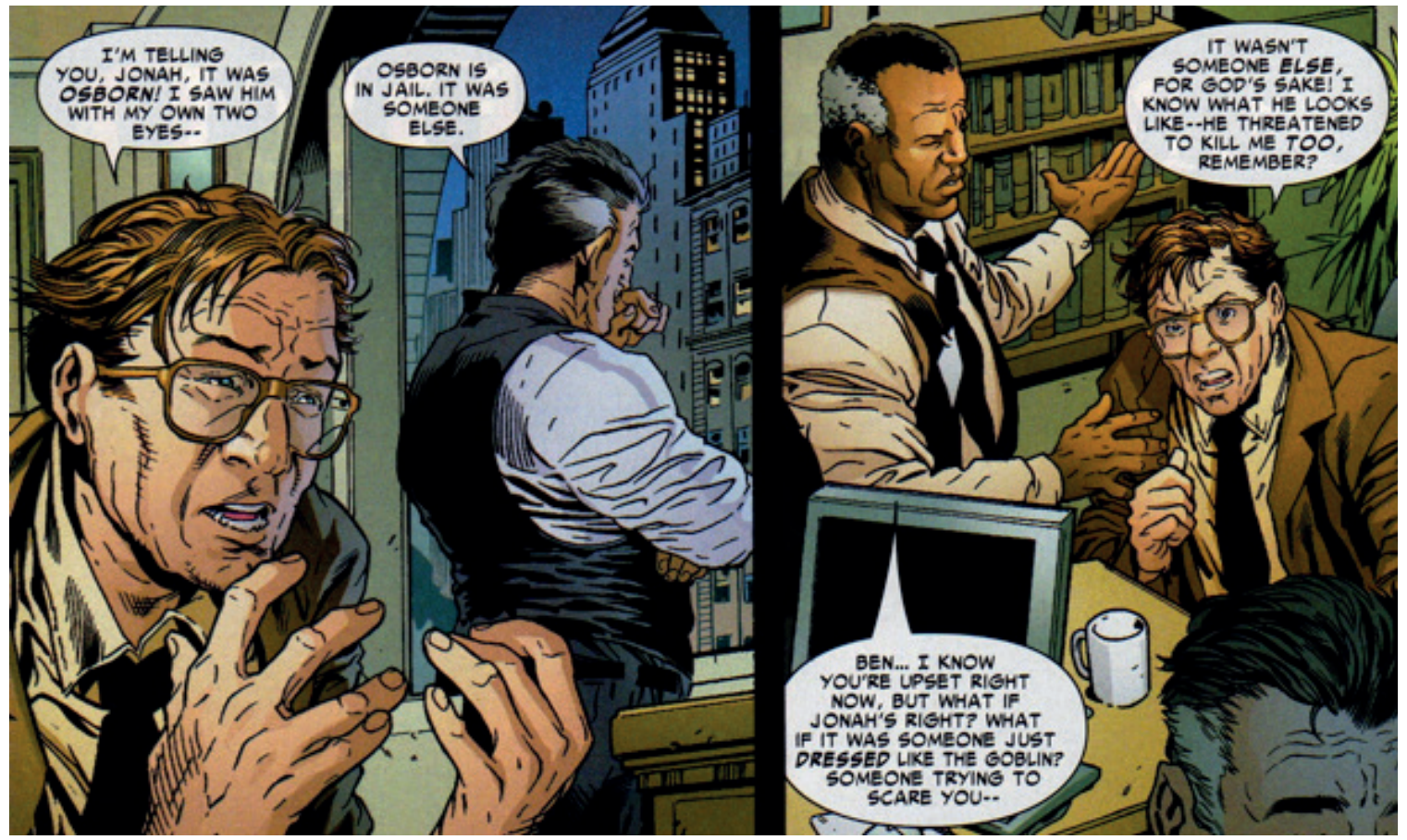

FIG. 3. VV. AA. Civil War. Front Line 10.

Nueva York, Marvel, 2006, p. 3.

12 Berganza Conde, M. R. Comunicación, opinión pública y prensa en la sociología de Robert E. Park. Madrid, Centro de Investigaciones Sociológicas, 2000, p. 84.

13 Ibid. p. 73.

${ }^{14}$ VV. AA. Civil War. Front Line 10. Nueva York, Marvel, 2006, p. 6. Citas extraídas de la edición original pero traducidas con la edición española: VV. AA. Civil War. Primera línea. Girona, Panini, 2007.

15 Serie limitada realizada por el guionista Paul Jenkins y los dibujantes Bachs, Lieber, Weeks y otros.

${ }^{16}$ Janoski, T. Citizenship and civil society: a framework of rights and obligations in liberal, traditional, and social democratic regimes. Cambridge, Cambridge University Press, 1998, p. 46. 
Aunque en Civil War los superhéroes son ciudadanos de todo derecho. Representan muchos de los valores del sistema dominante en los Estados Unidos (la mano dura con el delincuente, la defensa de los valores de una sociedad democrática, la justicia, etc.). ¿Por qué los condena la opinión pública? Por una parte a causa de que la desgracia en la que mueren decenas de niños y niñas es vivida en directo, en medio de comentarios sarcásticos y banales (dirigidos únicamente por criterios de subir audiencia). Otro factor es la entrada en vigor casi automáticamente del Decreto de registro de superhumanos, que exige un posicionamiento inmediato.

Las críticas al lenguaje de guerra fueron descalificadas por quienes veían en ellas un ejemplo de la consabida actitud académica de quienes viven encerrados en sus torres de marfil y, sobre todo, por quienes inmediatamente se sumaron al coro del «prietas las filas» que ha arrasado como un huracán la opinión pública y trata de obligar a cada quien a tomar posición en términos maniqueos, tal y como los formuló explícitamente el presidente Bush en una de sus primeras intervenciones ante el Congreso de los EE. UU.: «con nosotros, o contra nosotros». Este es uno de los peores efectos colaterales de la crisis, una nueva manifestación de pensamiento único que constituye una amenaza letal para la democracia. ${ }^{17}$

Dice Sally, la reportera de izquierdas de Primera linea: «ay, Dios mío... Es que ya me lo imagino. Damas y caballeros... en la esquina roja, la constitución de los Estados Unidos. En la esquina azul, su imparable equipo productor de desinformación y paranoia, ganador por dos caídas y una decisión del árbitro». ${ }^{18}$ Vemos que se define a los medios como «equipo productor de desinformación y paranoia», lo contrario de lo que tendrían que ser.

It is thus about the marginal adjustments in such rights that practical-minded judges make when the values that underlie the rights — values such as personal liberty and privacy - come into conflict with values of equal importance, such as public safety, suddenly magnified by the onset of a national emergency. ${ }^{19}$

Vemos dos posiciones enfrentadas, una a favor de los derechos civiles y la otra a favor de la seguridad nacional. Estas dos posturas están representadas en el cómic a través de Sally y Ben, los dos periodistas. Dice Sally que su periódico le ha dado

carta blanca para escribir acerca de los recortes a las libertades civiles en América. Y voy a relacionarlo con las intervenciones telefónicas. ¿Y tú? /[Ben] - Jonah me dijo... cita literal: se lo vamos a meter por el culo a los progres hasta tan arriba que pensarán que la página de deportes del miércoles es la edición dominical. ${ }^{20}$

\footnotetext{
${ }^{17}$ Chornet, C. R. Op. cit., p. 241

${ }_{18}$ VV.AA. Op. cit., n. ${ }^{\circ} 1$, p. 5.

19 Posner, R. A. Op.cit., p. 1.

${ }^{20}$ VV. AA. Op. cit., n.o 1, p. 5.
} 
Parece que el conflicto es a nivel de rebeldes y conformistas, o de prensa de izquierdas y prensa de derechas. También influye que algunas de las figuras del star system superheroico se posicionen a favor del registro (Iron Man y Spiderman). Pero ninguno de estos motivos parece suficiente para justificar las medidas tan drásticas que adopta S.H.I.E.L.D., que acaban causando la muerte del superhéroe Goliat. Podemos entender el crossover como una extensión de los sentimientos de la opinión pública americana. A través de él se expresa la neurosis imperante y se plantea un tema profundamente político: el recorte explícito de libertades civiles a causa de la prevención de riesgos (las autoridades quieren impedir que se repita el caso que hace arrancar la historia). Este recorte lleva a deshumanizar y a criminalizar a aquellos que eran más que humanos y a la vez la máxima representación de la lucha por la justicia, sus héroes.

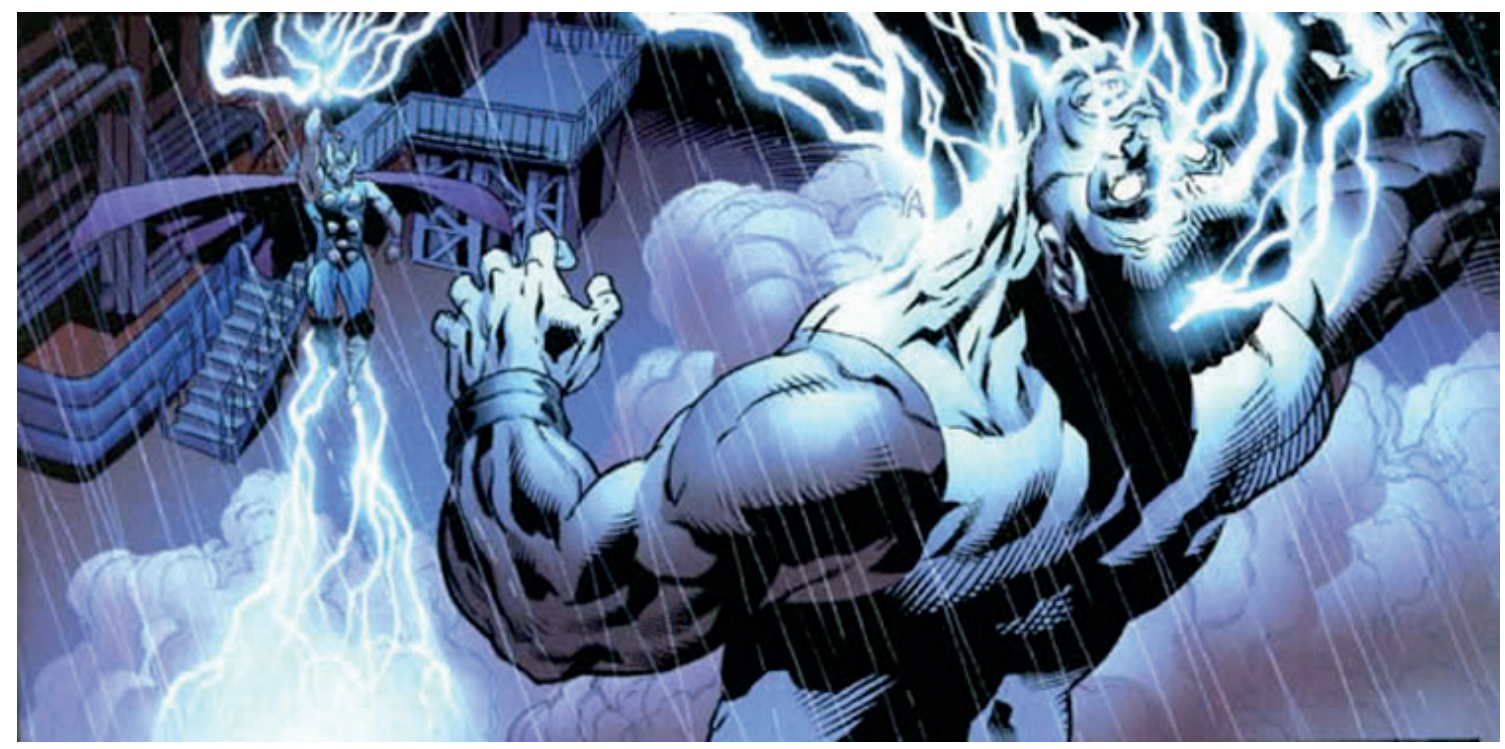

FIG. 4.VV.AA. Op. cit., n. ${ }^{\circ}$ 6, p. 10.

Los héroes de un pueblo representan los ideales de ese pueblo, o como mínimo los códigos míticos bajo los que actúa la población. En las sociedades posfordistas el fenómeno mitopoyético se traslada a las estructuras de producción masiva de información, los medios de producción masiva. De esta manera una parte de la mitología de los norteamericanos está en uno de sus mayores productos de consumo: el cómic. Los superhéroes son algunos de los mitos actualmente existentes. «El mundo necesita a los Vengadores. Los mejores de los mejores. Los mejores y más destacados. Símbolos. Iconos. Es hora de sanar. Es hora de decirle a la gente que cuidamos de ellos». ${ }^{21}$ Con la deshumanización de sus propios mitos y consecuentemente de su propia cultura se puede hablar de una cierta deshumanización de la sociedad, necesaria para aplicar la non-legal law of necessity, que implica dejar de lado algunos derechos democráticos, barbarizarse para luchar contra el bárbaro. Por eso se habla de sanarse, curarse del mal de la seguridad nacional. Los únicos que lo tiene claro al principio

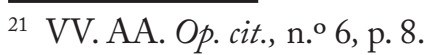


son Sally y los héroes antirregistro: «Ben, sabes tan bien como yo que están burlando la constitución. Tenemos la obligación de hacerlo público, independientemente de la empresa para la que trabajemos». ${ }^{22}$

\section{La lógica maniquea: amigo/enemigo}

El hecho de aplicar un tipo de leyes que restringen los derechos de algunos de los ciudadanos que habitan en el país,

supone la adopción de la lógica de la guerra en el orden interno. Es paradigmática a ese respecto la aprobación de lo que conocemos como «USA Patriot Act» cuyas siglas corresponden a una expresión mucho más explícita («Uniting and Strengthening America by Providing Appropriate Tools Required to Intercept and Obstruct Terrorism Act», es decir, Ley para unir y robustecer América mediante la provisión de los Instrumentos Adecuados para interceptar y obstruir el terrorismo). ${ }^{23}$

También los periodistas de Primera línea se dan cuenta de este fenómeno que empezó con toda la política post 11-S:

Es probable que Ben tenga razón. Todo esto empezó el día en el que unos extremistas furiosos decidieron estrellar un par de aviones contra unos edificios muy altos de Manhattan. Entonces nos pusimos en modo «lucha», y ahora volveremos a hacerlo./ De pronto el periodismo se subordina a las necesidades de la retórica patriotera, y empieza la lucha por los sentimientos de una nación. Libertad civil contra comodidad civil; intervenciones telefónicas contra terrorismo; FOX contra CNN. ${ }^{24}$

\section{Habla Consuelo R. Chornet de la lógica del estado de excepción que tiene como conse- cuencia crear este estado de guerra:}

Ese nuevo orden empieza por debilitar las exigencias del Estado de Derecho en el ámbito estatal, en EE. UU., pero también en otros países, incluso de la UE, como el Reino Unido. Supone la implantación de una lógica de Estado de excepción en no pocos ámbitos, mucho más allá del conocido limbo jurídico que sufren los prisioneros del Delta Camp, en Guantánamo. Una lógica de excepcionalidad, supuestamente justificada por la gravedad del peligro («estamos en guerra»y, de hecho, en los EE. UU. se vive en ese estado de guerra) que exige medidas excepcionales para poder combatir con eficacia. Un discurso que, insisto, no puede dejar de contaminar principios básicos del Estado de Derecho, de la democracia, incluso de la política, pues significa que la lógica de la guerra sustituya paulatinamente al verdadero discurso político, más allá del viejo dictum de Klausewitz. En efecto, la lógica propuesta a partir del 12 de septiembre implica la imposición de la dialéctica maniquea amigo / enemigo (la concepción propuesta por Schmitt), como único discurso de la política, que contamina principios elementales de legitimidad democrática en el orden interno y en el internacional. ${ }^{25}$

\footnotetext{
${ }^{22}$ VV.AA. Op. cit., n.o 4, p. 3.

${ }^{23}$ Chornet, C. R. Op. cit., pp. 236-237.

${ }^{24}$ VV. AA. Op. cit., n. ${ }^{\circ} 1$, p. 6.

${ }^{25}$ Chornet, C. R. Op. cit., pp. 237-238.
} 
Vemos como el principal problema está en el hecho de la creación de una dinámica de buenos y malos, de los de aquí y los de allá, del amigo y del enemigo, una dinámica que solo puede terminar en un: «estás conmigo o contra mí», y que implica medidas duras contra los que se considera que están contra uno mismo. Cuando Sally y Ben, al final de Primera línea, hablan con Tony Stark (Iron Man), le explican que han descubierto las verdaderas razones que han motivado el decreto (los beneficios de la industria armamentística en la que Stark está muy metido), además saben que la excusa de la guerra contra Atlantis era para construir un enemigo común y terminar con la disidencia.
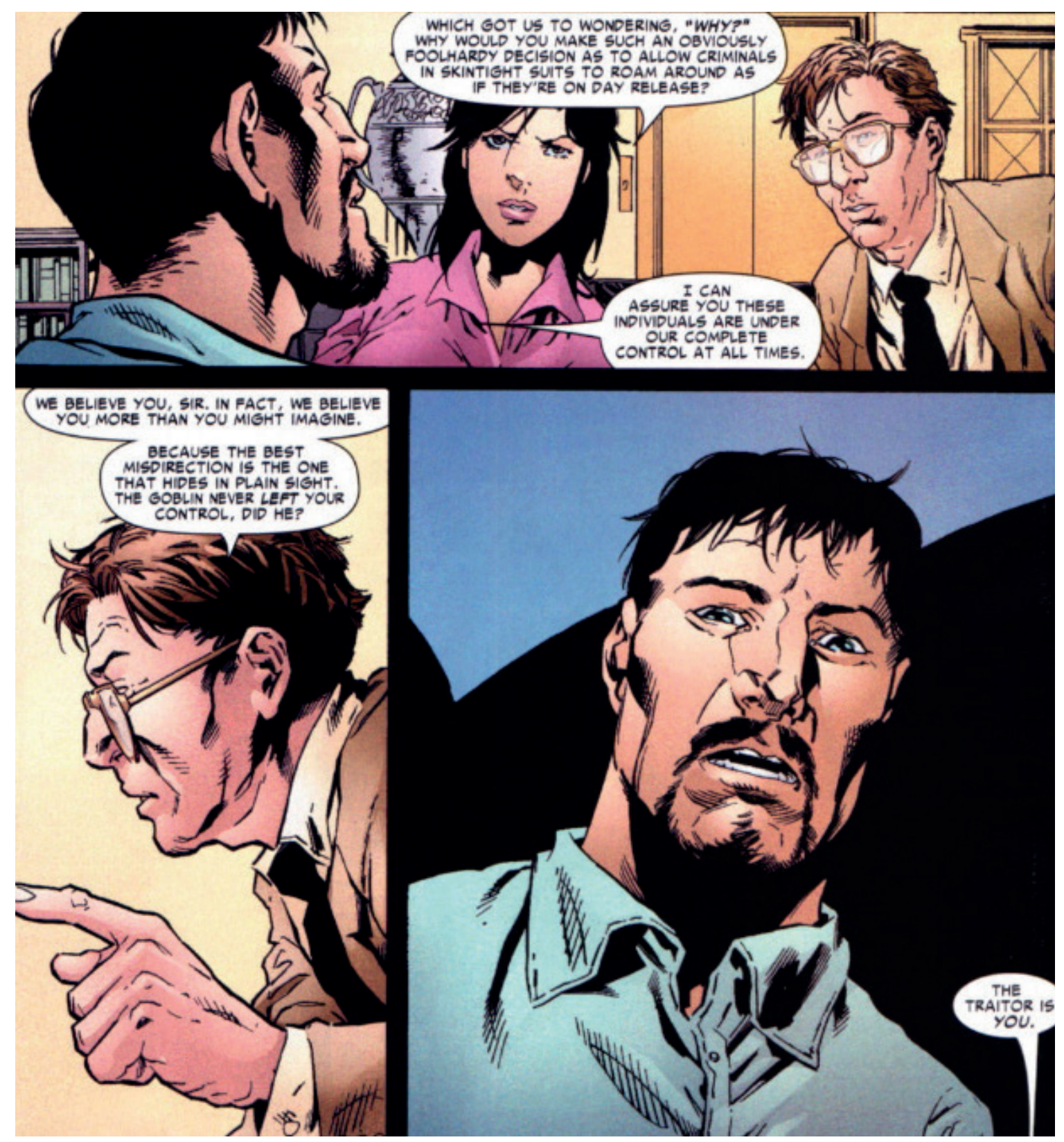

FIG. 5.VV. AA. Op. cit., n.o 11, p. 26. 
Sabía que el decreto sería sumamente impopular. Sólo usted estaba dispuesto a formular la mayor apuesta de la historia, porque sabía cuáles serían sus beneficios. La mera posibilidad de una guerra contra Atlantis ha incrementado en más de un 38\% el número de héroes registrados en los últimos diez días, porque todos ellos quieren unirse a la lucha contra el enemigo común. ${ }^{26}$

La construcción de un enemigo común para mantener los ingresos de la industria armamentística es una de las claves para la comprensión del mundo desde la guerra fría hasta nuestros días. Es decir, sin caer en la conspiranoia, y creer que los que nos gobiernan están completamente a la merced de grandes lobbys armamentísticos, se puede decir que los beneficios son tan grandes que se encuentran causas para justificar estos beneficios, como sería el miedo o la necesidad de protegerse. Hay dos corrientes que actúan en la misma dirección: el miedo y los intereses económicos. De esta manera, el miedo se proyecta en el enemigo, porque es aquel capaz de hacernos daño o de atacar lo que hemos conseguido con el sudor de nuestras frentes (la democracia, la libertad, etc.). El problema es que para defender esta libertad se aplica una lógica maniquea que acaba en la restricción de derechos de los ciudadanos. Así, aparece otro punto de vista, el que cree que los verdaderos enemigos son los que construyen esta lógica maniquea que conduce a la imposición de la lógica de la seguridad nacional, y que se encarga de restringir aquellos ideales por los que algunos han trabajado y luchado. Dice el superhéroe Tipógrafo a Sally: «he luchado por mi país en el extranjero, srta. Floyd. ¿Acaso he peleado por la libertad para que luego se transforme aquí mismo en mera fachada sin sustancia?». ${ }^{27} \mathrm{Y}$ sigue diciendo:

Vi morir a mi hermano Joey en frías arenas extranjeras, srta. Floyd. Sacrificó la vida por la primera enmienda, por la libertad de expresión y de reunión, por el derecho a la privacidad.../—¿A la privacidad? ¿De qué país hablabas? [interrumpe Battlestar]/Hay algo que quiero saber. Nuestros gobernantes han tomado la decisión de cazar a su propia gente como animales, tan sólo porque defienden su derecho a la privacidad... y el motivo es que unos idiotas hicieron una estupidez en Stamford y alguien tiene que pagarlo. ¿Acaso han olvidado quién es el verdadero enemigo? ${ }^{28}$

\section{La libertad y el derecho a la disidencia}

Podemos deducir que para los superhéroes Tipógrafo y Battlestar lo primordial es la defensa de las libertades y de los derechos civiles, y que el verdadero enemigo es aquel que promulga las leyes que rescinden esas libertades. El problema, como veremos, es que la defensa de la libertad o de los grandes ideales ha perdido su sentido porque se ha convertido en una consideración demasiado abstracta. La recuperación del valor real y concreto que tienen los grandes conceptos se puede realizar a través de la relación con los derechos escritos. $\mathrm{Ri}$ chard King dice: «rights [...] are particular specifications on and codifications of freedom

\footnotetext{
${ }^{26}$ VV.AA. Op. cit., n. ${ }^{\circ} 11$, p. 27.

${ }^{27}$ VV.AA. Op. cit., n. ${ }^{\circ}$ 3, p. 5.

28 Idem.
} 
in general». ${ }^{29} \mathrm{La}$ idea de libertad se codifica a través de derechos concretos, por lo tanto, pisotear esos derechos implica pisotear la propia idea de libertad. Por ejemplo: cuando nos referimos a la libertad nos estamos refiriendo a los treinta artículos que forman la Declaración universal de los derechos humanos; o a los principios y libertades que aparecen en la constitución de un país concreto; o a la recuperación de unos espacios que consideramos que han sido pisoteados por alguna entidad estatal, etc. De esta manera, los espacios legales que ha pisoteado la USA Patriot Act son

the attempt to deny the right of habeas corpus to captured terrorist suspects, the interception of phone calls and other electronic communications, such as e-mails, of U.S. citizens by the National Security Agency outside the limits set by the Foreign Intelligence Surveillance Act; ambitious data-mining projects such as the military's Able Danger project; demands by the FBI under section 215 of the USA Patriot Act for records of library borrowings; monitoring of the constitutionally protected speech of radical imams; torture or quasi-torture of terrorist suspects; and establishment of military tribunals to try suspected terrorists, including U.S. citizens apprehended in the United States rather than on a foreign field of combat such as Afghanistan or Iraq. ${ }^{30}$

«At one time the free world included several nations ruled by highly repressive regimes, while the mechanisms of the free market may severely restrict my comings and goings. The infamous Rousseauean claim that we may force people to be free has bothered more than just conservatives». ${ }^{31}$ No se puede forzar a nadie a ser libre, y menos restringiendo sus propios derechos y estableciendo regímenes represivos. O como mínimo, al hacerlo, tiene que existir el derecho a rebelarse contra el estado que esté aplicando dicha legislación injusta, como bien se recoge en la Declaración universal de los derechos humanos.

El preámbulo de la Declaración universal de los derechos humanos dice que es «esencial que los Derechos Humanos sean protegidos por un régimen de Derecho, a fin de que el [súper] hombre no se vea compelido al supremo recurso de la rebelión contra la tiranía y la opresión». Desde una perspectiva estrictamente ceñida a los derechos humanos la USA Patriot Act no es internacional ni universalmente válida, ya que vulnera veintiún artículos de la declaración. Deduzco que tal régimen no puede ser considerado válido en un estado de Derecho, ni tan siquiera como estado de excepción ya que la excepción es la regla. Así, tal régimen recibe el nombre de tiranía. En Civil War, la resistencia, el grupo liderado por el Capitán América, no piensa dar su brazo a torcer y sigue unos principios idealistas, pero a la vez concretos. Dice el Capitán:

Creo en las libertades fundamentales que nos confiere nuestra constitución, Ben. Creo que tenemos derecho a llevar armas, derecho a defendernos y derecho a elegir. He jurado defender a los

\footnotetext{
${ }^{29}$ King, R. H. Op. cit., p. 14.

30 Posner, R. A. Op. cit., p. 2.

31 KING, R. H. Op. cit., p. 12.
} 
Estados Unidos de las fuerzas que los amenacen desde fuera, y también desde dentro. Si para ello tengo que levantarme contra mi propio gobierno y rechazar una ley ilegitima que han aprobado mis superiores... pienso que ese es mi deber. ${ }^{32}$

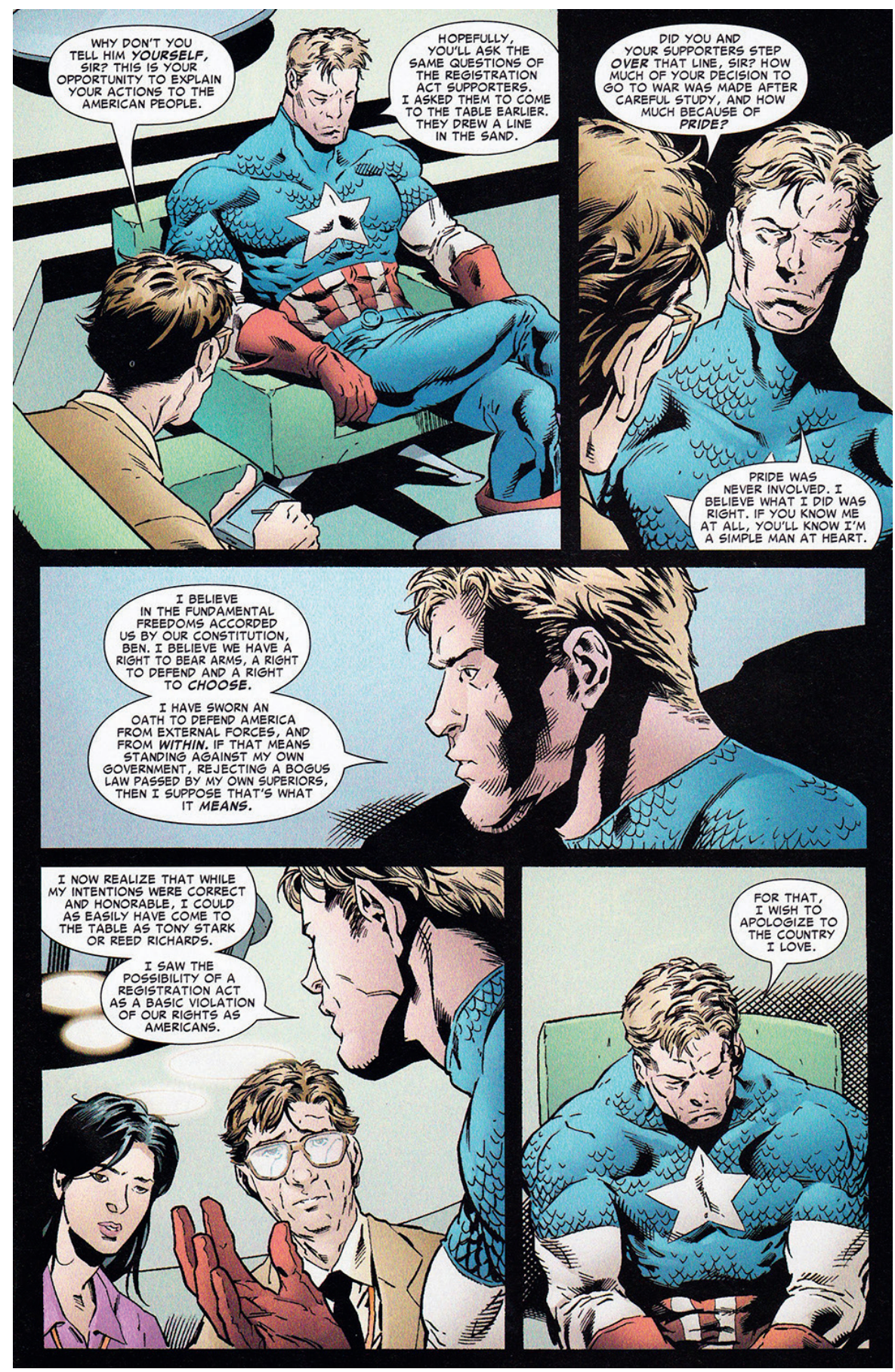

FIG. 6. VV. AA. Op. cit., n. ${ }^{\circ} 11$, p.12.

32 VV.AA. Op. cit., n. ${ }^{\circ} 11$, p. 12. 
De esta manera, hay unos personajes que se dedican a la defensa de las libertades fundamentales, algo así como las libertades más abstractas, los ideales a los que debería tender una sociedad para volverse más libre y justa, las libertades más básicas que recoge el habeas corpus. Los que se levantan contra el sistema lo hacen indignados por lo que está pasando a su alrededor. Si el contexto se aleja demasiado del ideal, entonces se producen distorsiones y restricciones en las propias ideas realmente existentes. Por ejemplo, un país que no es nada democrático, pero que su régimen se define como democracia, devalúa el propio concepto de democracia y hace que la única manera de defender a la democracia sea volviendo al término más idealista. En estos términos se plantea el duelo dialéctico entre Sally y el Capitán América. Sally como la reportera ya frustrada, integrada en el sistema, que acepta su contexto como lo mejor que hay (el mejor de los mundos posibles) y el Capitán como el último defensor de un ideal, criminalizado y detenido por su disidencia.

El problema es que está peleando por un ideal... no sabe hacer otra cosa. América ya no es el país
de mamá y de las tartas de manzana... es el país del colesterol, y de Paris Hilton, y de cómo subir
a patadas hasta la cumbre. El país al que yo quiero trata a sus famosos como a reyes y a sus maestros
como a una mierda, pero al menos camino todos los días por sus calles. Al menos sé cómo es. ${ }^{33}$

La exigencia de conocer el mundo real y aceptarlo tal como es, parece ser la exigencia que le hace Sally al Capitán. Lo que se está diciendo es que los ideales nos alejan de la realidad y no nos permiten conocerla. El Capitán América no opina lo mismo. Cree que los ideales se fundamentan en un descontento ante la realidad que nos rodea y este descontento implica un conocimiento de aquellos aspectos que no nos agradan: «vi que la posibilidad misma de un decreto de registro constituia una violación de nuestros derechos básicos como estadounidenses», ${ }^{34}$ los otros personajes se pierden entre consideraciones de interés propio. Es completamente absurdo el momento en el que Sally descalifica al Capitán América por no conocer Myspace, ${ }^{35}$ como si no conocer Myspace tuviera consecuencias graves para la justicia. Lo que es realmente grave es perder de vista los ideales, las ideas que no son más que motores para transformar la realidad hacia esos lugares en los que nos gustaría vivir, los motores hacia un mundo más justo y más libre. El Capitán tiene claro que «like equality before the law, the possibility of being just is something that presupposes freedom». ${ }^{36} \mathrm{Es}$ decir, que sin libertad no existe la posibilidad de ser justo. El personaje de la reportera $\mathrm{Sa}-$ 1ly, en un ataque de rebeldía redundante se rebela contra la rebeldía, como si el superhéroe fuera algo así como una representación de la generación de su abuelo y de las ideas que defendieron contra los nazis y ella le gritara las virtudes de la nueva generación que se ha olvidado de los ideales pero tiene Myspace. Aunque la conversión de este personaje en un títere es patética, es muy representativa de la actitud que se ha adoptado algunas veces en

\footnotetext{
33 Ibid.p. 16.

34 Ibid.p. 12.

35 Ibid.p. 13.

${ }^{36}$ KING, R. H. Op. cit., p. 15
} 
las sociedades de consumo: «esto es lo que hay, y no se puede hacer nada para cambiarlo, acéptalo, abuelo». Es el mismo mundo en el que la palabra utopía se ha cargado con consideraciones negativas, y en el que cualquier opción política de izquierdas que triunfe es descatalogada como poco realista. Se produce un

efecto de criminalización de la disidencia, de la libertad de expresión y crítica, del pluralismo. Un efecto criminalizador que ha afectado en primer lugar a los colectivos más vulnerables, los inmigrantes, los demandantes de refugio y asilo, a los que se ha extendido, en los EE. UU. pero también en Europa, la vieja doctrina nazi de los Gemeinschaftsfremde, es decir, de los «extraños a la comunidad», que propicia el recurso a lo que se ha denominado «derecho penal del enemigo», incluso el recurso a un «derecho penal de guerra». ${ }^{37}$

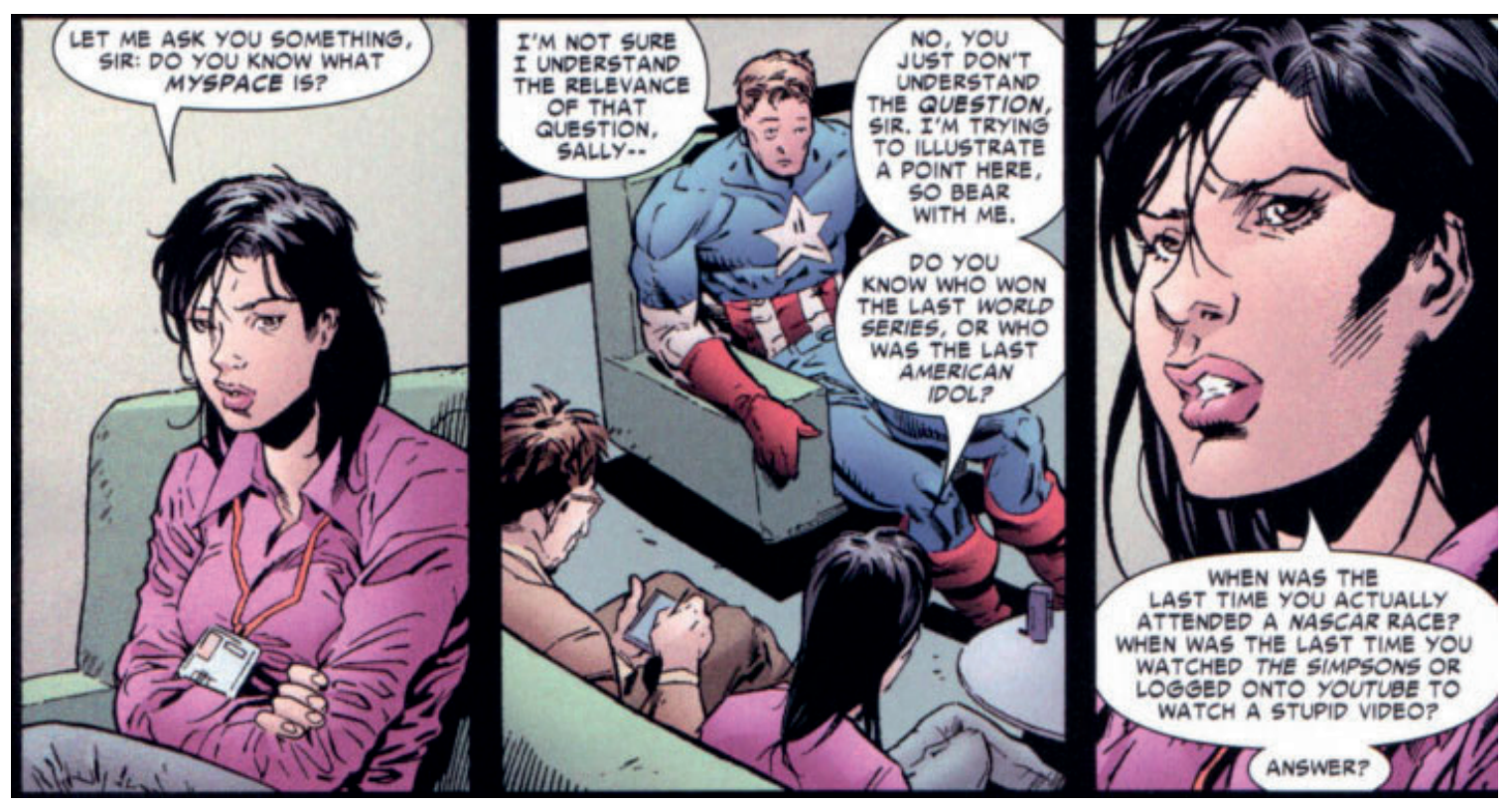

FIG. 7. VV. AA. Op. cit., n. ${ }^{\circ}$ 11, p. 14.

De esta manera, si consideramos a los superhéroes antirregistro disidentes que luchan por la libertad podemos reconocer su derecho a defenderse. Ya que, si un estado ha promulgado una ley que se basa en un «derecho penal de guerra» y aplica violencia sistemática contra determinados sectores, es normal y lógico que esos determinados sectores se levanten en armas. Sin meternos en las acciones de este grupo, parece ser que sus ideales desde una perspectiva ética son más o menos acertados, pero siempre comprensibles en cuanto a grupo oprimido que busca un espacio donde desenvolverse en libertad. «Los terroristas para unos son freedom fighters para otros, y la historia está llena de ejemplos recientes de ese doble rasero: [Iron Man y el Capitán América]», ${ }^{38}$ o el grupo de Atlantes que iban [parece ser]

\footnotetext{
37 Chornet, C. R. Op. cit., p. 238.

${ }^{38}$ Ibid., p. 246.
} 
a matar al supervillano Nitro porque uno de los superhéroes muertos estaba emparentado con la realeza Atlante: «unos los llaman terroristas y, los otros, luchadores por la libertad». ${ }^{39}$

La fuerza que mueve a las tropas disidentes es esta libertad que es pura pasión ante la injusticia. Dice el Tipógrafo ante la perspectiva que le plantea Sally de que son pocos y es difícil encontrar a los demás: «los encontraremos, igual que nos encontramos entre nosotros. Y seguiremos adelante. No se les puede arrebatar la libertad a los corazones». ${ }^{40}$ Otro argumento es el que da Solo: «no podemos cambiar las normas cada vez que algo explota. Sería una victoria de los que ponen las bombas. ¡Y mientras yo viva, el terror morirá!». ${ }^{41}$

$\mathrm{El}$ terror es generado por el estado, no por el terrorismo. Y este terror se genera para allanar el camino a la sociedad del control. Esto se hace evidente si hacemos un repaso de lo que hemos dicho en relación a los medios y a sus mecanismos de generación de sentido. Además de las políticas de verdadero terror que se aplican en algunos espacios alegales, tema que comentaremos más adelante. Si el estado hace concesiones al terror, es decir, sacrifica su libertad por miedo, y sacrifica la libertad de sus ciudadanos, vence el régimen del miedo y la industria de la seguridad. Este es el verdadero enemigo contra el que luchan los superhéroes antirregistro.

\section{La brutalidad estatal}

Las fuerzas de intervención de S.H.I.E.L.D. son los encargados de aplicar la brutalidad del estado para cumplir la ley. Son policías armados con trajes que impiden que se les vea la cara. Esta visión goyesca de la autoridad deshumaniza a los policías y los convierte en clones violentos que actúan siempre según las órdenes. El propio Iron Man parece razonable cuando está sin su traje, una vez dentro se transforma en un agente de la ley vestido de robot, capaz de acompañar sus bonitas palabras con potentes explosivos. Es necesario que las fuerzas de coacción se disfracen para convertirse en el brazo armado de la institución a la que representan. Los hombres debajo de los trajes tienen que olvidarse mientras hacen su trabajo de su humanidad para cumplir las órdenes con una férrea disciplina. No hay discusión, si usted incumple la ley, será detenido y se le mandará a una cárcel sin un proceso justo. Las fuerzas del orden no intentan hacer respetar la ley, ya que la propia ley de registro es injusta e incumple muchos artículos de la Declaración universal de derechos humanos, las fuerzas del orden intentan que se respete al gobierno y sus decisiones. Su función es básicamente coactiva. Para cumplir con estas decisiones hay que ensuciarse las manos, y para hacer el trabajo sucio es mejor olvidarse de que uno mismo comparte algo con aquellos a los que está reprimiendo. De la misma manera que hay que deshumanizar a un grupo determinado para poder prescindir de sus derechos, y hay que deshumanizar a la sociedad para crear el

\footnotetext{
39 VV.AA. Op. cit., n.o 5, p. 3.

${ }^{40}$ VV.AA. Op. cit., n. ${ }^{\circ}$ 3, p. 4.

${ }^{41}$ Ibid., p. 5.
} 


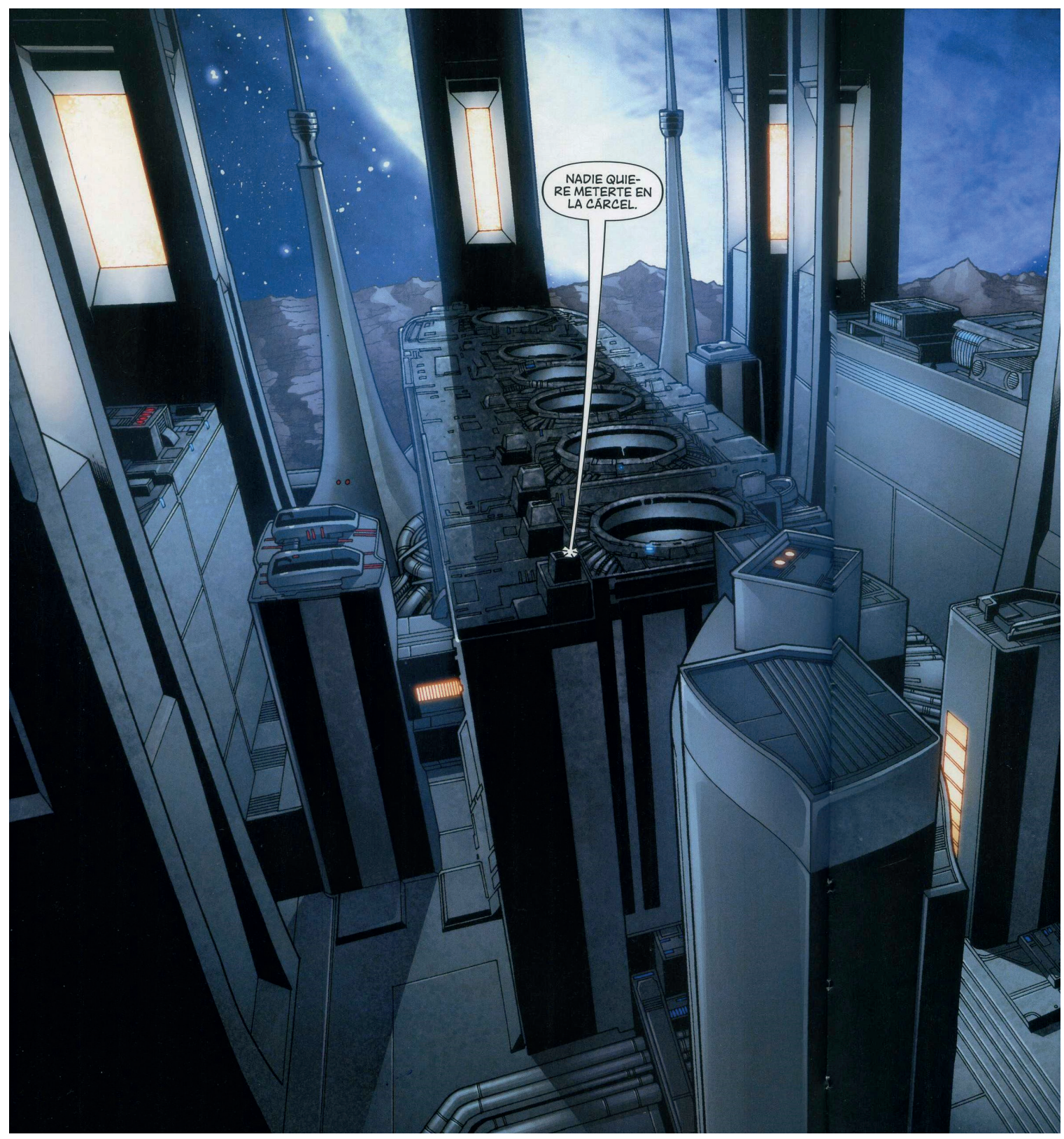

FIG. 8. Millar, M. y McNiven, S. Op. cit., p. 135.

clima adecuado para según qué prácticas, hay que deshumanizar la ley y a los encargados de aplicarla. Esta se convierte en un simple brazo entrenado para golpear y detener a aquellos que se supone que son sus enemigos. Pero esta deshumanización no se podría dar sin el amparo (o el vacío) de la legislación existente, que lleva a cabo la política de la vista gorda ante los hechos y las costumbres de la violencia policial o militar. Es significativo que cuando los periodistas Sally y Ben dejan de ser críticos con el sistema, se vea una viñeta en la que se oye el pensamiento de Ben que dice: «la vida en la ciudad volvía a ser normal» y aparezcan policías armados hasta los dientes. Podemos interpretar esta viñeta como una representa- 
ción de esta política. Los criterios de normalidad se han convertido en los criterios de la seguridad nacional. ${ }^{42}$

Durante la estancia en prisión de Robert Baldwin (alias Bola Veloz), vemos una representación de lo que sería una cárcel alegal como el Delta Zone de Guántanamo. Un lugar en el que aplicar sin restricciones toda la brutalidad posible. Baldwin es el chivo expiatorio de todo lo que ha pasado (él estaba en el reality show que terminó con la muerte de sesenta personas). Al héroe lo encuentran casi muerto y la agencia S.H.I.E.L.D. (clara alegoría de la CIA) se lo lleva a la prisión, lo retiene sin presentar cargos contra él e impide que reciba un juicio justo. El ex superhéroe (ha perdido sus poderes con la explosión) es incitado a que se registre y él se niega porque eso sería reconocer su culpabilidad. «Pero si no hice nada malo», dice Baldwin. Pero sí que hizo algo: estar en el sitio equivocado en un momento político convulso. Primero lo llevan a una prisión de alta seguridad en la que es apaleado y maltratado por guardias y presos. Lo despojan de derechos y lo torturan. «He dicho que quiero ver a mi abogado. No pueden retenerme aquí. Han pasado más de tres días. No tienen derecho a esto. Eh... oye, tío, ¿̇me estás escuchando? ¡Como ciudadano americano, tengo derecho a un abogado! Tienes que presentar una acusación formal o soltarme...-Cállese, Sr. Baldwin. - ¡Conozco mis derechos y exijo un abogado!/Usted es un combatiente no registrado, Sr. Baldwin. Sus derechos los decido yo.» ${ }^{43}$ Vemos cómo se cumple lo que decíamos, el individuo que está fuera de la ley, también está fuera de la protección de la ley, a merced de la brutalidad de las fuerzas coactivas. El mote Asesino de niños que le ponen en la prisión es muy representativo: Robert representa al monstruo, al otro, al freak extraño a la comunidad que es capaz de canalizar los odios inherentes a la propia comunidad. Todos lo odian: la opinión pública, sus compañeros de cárcel, los guardias. Baldwin mantiene sus principios hasta el final: «diles que aceptaré el día en que el infierno se congele», ${ }^{44}$ le dice a su abogada cuando le propone que se registre. El día en que le vuelven los poderes superheroicos y hace explotar a su contrincante y a los espectadores de un combate de boxeo ${ }^{45}$ lo trasladan a la Zona Negativa.

¿Dónde está la Zona Negativa? «No está cerca de ningún lugar. Puede que no sea un lugar en el sentido genuino de la palabra. Viene a ser, más bien, un estado del ser», le dice el Tipógrafo a Robbie, que como Virgilio a Dante, le sirve de guía en su entrada en el infierno. «La Zona Negativa produce ciertos efectos en algunas personas». ${ }^{46}$ Seguidamente vemos a Coldblood tirado en el suelo diciendo que morirá antes que volver a verse a sí mismo. Parece que la Zona Negativa despierta también los propios demonios, además de los demonios de la autoridad. Llegamos al edificio ciclópeo donde están las distintas prisiones de la zona, a Robbie le toca la prisión Alpha (la Isla Fantasía). Esta es una prisión brutal y totalmente

\footnotetext{
${ }^{42}$ VV.AA. Op. cit., n. ${ }^{\circ}$ 11, p. 22.

${ }^{43}$ VV. AA. Op. cit., n. ${ }^{\circ}$ 2, p. 17.

${ }^{44}$ VV.AA. Op. cit., n. ${ }^{\circ}$ 3, p. 22.

${ }^{45}$ VV.AA. Op. cit., n. ${ }^{\circ}$ 4, p. 20.

${ }^{46}$ VV.AA. Op. cit., n. ${ }^{\circ}$ 5, p. 19.
} 
deshumanizada. Los superhéroes son sometidos a todo tipo de tormentos. En la parte de «El acusado» que está narrado en la fricción entre el género epistolar y la dura realidad damos una vuelta por la prisión: vemos celdas pequeñas con el suelo de tierra, Robbie nos explica el suicidio de Digitek. Estrella de Combate se retuerce de dolor por un cascote de metralla que se le incrustó en el espinazo cuando lo detuvieron las fuerzas de S.H.I.E.L.D. en una reunión secreta. Finalmente el héroe sale de la cárcel para hablar ante América pero, en un claro paralelismo con el asesinato de Lee Harvey Oswald, aparece un padre de una de las niñas muertas en Stamford y le dispara en el abdomen. Las palizas sistemáticas, el sufrimiento innecesario y la presión psicológica (representada en la reacción de Coldblood) son las características de este lugar que es un estado del ser, es decir, un no-lugar, más allá de la protección jurídica de los estados de derecho.

Interrogado acerca del uso de la tortura de prisioneros en las cárceles de Guantánamo y Abu Ghraib, Cheney admitió que los torturados eran vestidos con «chalecos explosivos, sus heridas escarbadas con un pie, sus dolores aumentados por pentotal sódico, la amenaza de cortarles los ojos» y otras lindezas por el estilo, ${ }^{47}$ como por ejemplo entre los métodos de tortura implícita o explícitamente autorizados por la Casa Blanca de Bush se encontraban retirarle medicinas a los detenidos, simular que se les ahogaba, el uso de serruchos para intimidar e informes falsos sobre la muerte de un hijo del detenido. ${ }^{48}$ Podemos ver como en las cárceles alegales establecidas por los Estados Unidos la situación de los detenidos es similar a la que sufre Robert Baldwin en la Zona Negativa. En el siguiente fragmento de la misma noticia vemos cómo el espacio alegal y el limbo jurídico creado por la non-legal law of necessity crean confusión y ambigüedad terminando siempre por perjudicar a aquellos que están bajo el «amparo» de dicho limbo:

En junio del 2003, el presidente se declaró en contra del uso de la tortura y a favor de castigar su uso. El abogado de la CIA protestó: la declaración presidencial confundía a los agentes autorizados por el propio presidente para usar «tácticas brutales» contra miembros de Al Qaeda. La Casa Blanca reiteró entonces su aprobación a las «tácticas brutales», pero ello, según el diario neoyorquino, no superó las tensiones internas del gabinete. Cheney - como lo comprueba su testimonio en el Senado- aprobó el uso extremo y secreto de la tortura e incluso la «desaparición» de los torturados. Condoleezza Rice, en cambio, recomendó el reconocimiento público de que EE. UU. tenía prisioneros terroristas. Alberto Gonzales, el malhadado procurador general, propuso entonces la teoría de la «inmaculada concepción»: llevar los prisioneros a Guantánamo, sin admitir que antes estuvieron secretamente detenidos. ${ }^{49}$

La renuncia a la tortura no es una renuncia ya que es la tortura la propia renuncia a los derechos humanos y a las libertades constitucionalmente reconocidas en los países democráticos.

47 Fuentes, C. «Estados Unidos: viejas y nuevas políticas», en Elpaís, Edición nacional, n.o 11667 (2009). Disponible en http://www.elpais.com/articulo/opinion/Estados/Unidos/viejas/nuevas/politicas/elpepuopi/20090521elpepiopi $4 /$ Tes.

48 Idem.

49 Idem. 


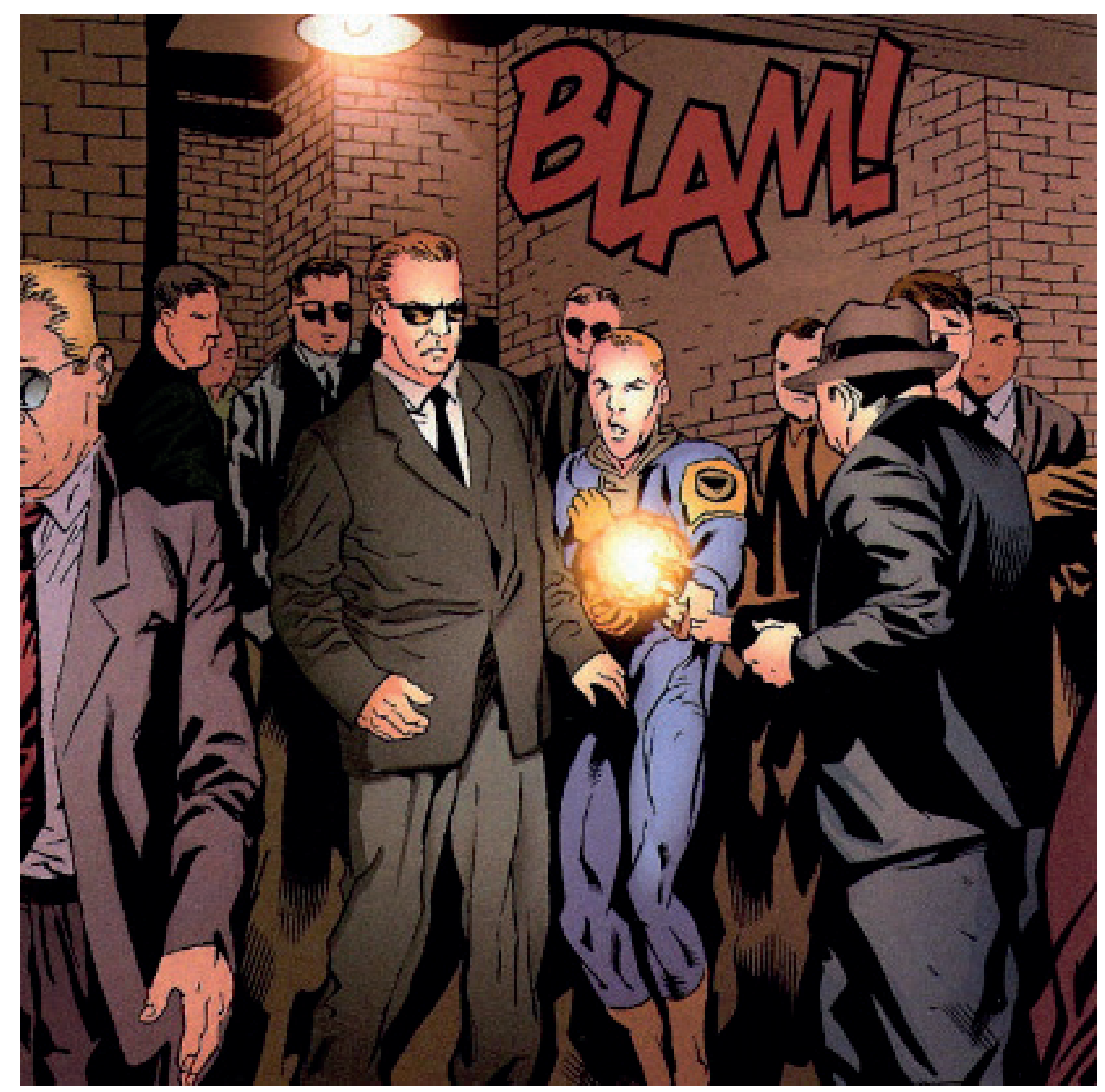

FIG. 9. VV. AA. Op. cit., n. ${ }^{\text {7, }}$ p. 5.

«Nosotros no torturamos», afirmó Winston Churchill cuando Londres era bombardeada por la Luftwaffe y doscientos individuos eran detenidos como espías. Renunciar a la tortura no es solo un imperativo moral. Es un imperativo racional que obliga a obtener la verdad con métodos que la comprueben, tarea más difícil que el fácil camino de una tortura al cabo poco confiable. ${ }^{50}$

El difícil camino del respeto a la democracia y la búsqueda de la verdad desde estos métodos es algo difícil teniendo en cuenta la cantidad de riesgos y problemas que existen, pero es el único camino que tienen las sociedades democráticas para continuar siendo democráticas.

50 Idem. 


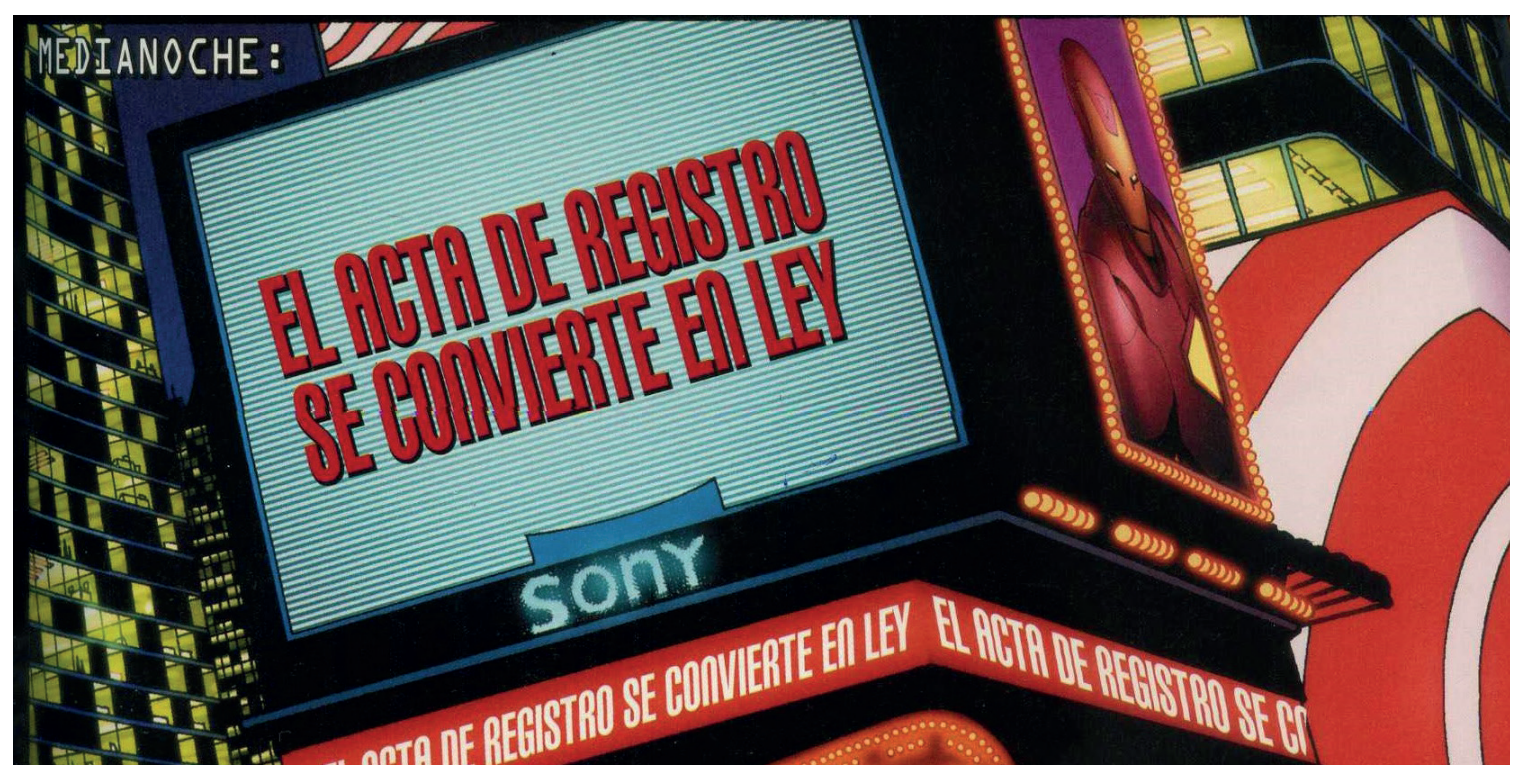

FIG. 10. Millar, M. y McNiven, S. Op. cit., p. 53 .

\section{Conclusión}

Hay varios argumentos para posicionarse a favor de los derechos civiles frente a los recortes en materia de derechos que invocan las doctrinas a favor de la seguridad nacional. El que nos parece más importante es el que construimos desde el punto de vista de los derechos humanos: la función de las democracias debe ser mantener en buena forma la salud de estos derechos. Si las democracias no los cuidan dentro de sus propias fronteras, ¿cómo van a ir a predicar a otros países sobre la fórmula adecuada para gobernar? Este punto de vista nos lleva a otro humanitarista: hay que cuidar la vida de cada individuo, o como mínimo de cada individuo que viva dentro de nuestras fronteras y que esté protegido por nuestras leyes. $\mathrm{El}$ problema aparece cuando estas leyes no protegen al individuo sino que lo despojan de derechos. Aun en el caso último de que todas las detenciones que se realizan por terrorismo implicaran a verdaderos culpables del cargo, habría que defender los derechos de estas personas. No nos podemos permitir regalar derechos a las fuerzas coactivas. La estrategia de la criminalización y la consecuente bipolarización del mundo en buenos y malos

lleva a exigir una lucha sin cuartel y, sobre todo, una lucha que bordea y frecuentemente vulnera los propios principios que dice defender. En aras de esa causa que tantas veces parece más una guerra santa, una cruzada [...], no importan los motivos de los terroristas, sus justificaciones. Como pudimos comprobar en la última reunión del comité específico sobre terrorismo del Consejo de Seguridad [...], la posición de quienes administran la doctrina correcta sobre la guerra contra el terrorismo es que no cabe preguntarse por las causas que invoquen los terroristas. No hay causa admisible ni relevante. Por decirlo de otro modo, esa guerra exige obediencia ciega al líder y a su estrategia. No es nada difícil predecir las consecuencias de semejante definición - a todas luces fundamentalista, malgret soi-, que no se harán esperar. ${ }^{51}$

${ }^{51}$ Chornet, C.R. Op. cit., p. 243 
«Todos nosotros vimos con temor cómo la nueva ley se aplicaba con violencia y eficacia./Se habrían podido debatir eternamente las razones. Pero nadie cuestionaba a quienes aplicaban la ley./ Nunca se hace, hasta que ya es tarde..${ }^{52}$ Dice Sally mientras observa cómo se detiene al superhéroe Prodigy. En nuestro caso, no es que no exista una opinión que cuestione a los que aplican la ley, si no que esta opinión no es suficientemente potente como para corregir las injusticias, lo que significa que las injusticias se alarguen y que para mucha gente la verdadera justicia llegue demasiado tarde.

${ }_{52}$ VV.AA. Op. cit., n. ${ }^{\circ}$ 2, p. 14. 
Civil War: Front Line. La confrontación entre seguridad nacional y derechos civiles

\section{BibliografíA}

Berganza Conde, M. R. Comunicación, opinión pública y prensa en la sociología de Robert E. Park. Madrid, Centro de Investigaciones Sociológicas, 2000.

Chornet, C. R. Derechos y libertades ante las nuevas amenazas a la seguridad global. Valencia, Universidad de Valencia, 2005.

Fuentes, C. «Estados Unidos: viejas y nuevas políticas», en El país, Edición nacional, n. ${ }^{\circ} 11667$ (2009). Disponible en http://www.elpais.com/articulo/opinion/Estados/Unidos/viejas/nuevas/politicas/elpepuopi/20090521elpepiopi 4/Tes.

GuÀrdia, C.y López, P. Els 11 del Raval. [Documental de televisión]. Televisió de Catalunya, 2009. Disponible en http://www.tv3.cat/30minuts/reportatges/1250/Els-11-del-Raval.

Janos KI, T. Citizenship and civil society: a framework of rights and obligations in liberal, traditional, and social democratic regimes. Cambridge, Cambridge University Press, 1998

KInG, R. H. Civil rights and the idea of freedom, Nueva York, Oxford University Press, 1992.

Millar, M. y McNiven, S. Civil War. Girona, Panini, 2007.

Ozu, Y. Buenos días: Ohâyo. [DVD]. A contracorriente films, Shochiku, 2013.

Posner, R. A. Not a suicide pact. the Constitution in a time of national emergency. Nueva York, Oxford University Press, 2006.

RosA, I. El país del miedo. Barcelona, Seix Barral, 2008.

VV. AA. . Civil War. Front Line. Nueva York, Marvel, 2006.

—Civil War. Primera linea. Girona, Panini, 2007. 